NASA/TM-2010-216902

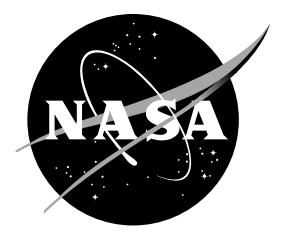

\title{
Polarization Dependent Coupling of Whispering Gallery Modes in Microspheres
}

G. Adamovsky and S. Wrbanek

Glenn Research Center, Cleveland, Ohio

B. Floyd

Sierra Lobo Incorporated, Cleveland, Ohio

M. Crotty

Glenn Research Center, Cleveland, Ohio 


\section{NASA STI Program . . . in Profile}

Since its founding, NASA has been dedicated to the advancement of aeronautics and space science. The NASA Scientific and Technical Information (STI) program plays a key part in helping NASA maintain this important role.

The NASA STI Program operates under the auspices of the Agency Chief Information Officer. It collects, organizes, provides for archiving, and disseminates NASA's STI. The NASA STI program provides access to the NASA Aeronautics and Space Database and its public interface, the NASA Technical Reports Server, thus providing one of the largest collections of aeronautical and space science STI in the world. Results are published in both non-NASA channels and by NASA in the NASA STI Report Series, which includes the following report types:

- TECHNICAL PUBLICATION. Reports of completed research or a major significant phase of research that present the results of NASA programs and include extensive data or theoretical analysis. Includes compilations of significant scientific and technical data and information deemed to be of continuing reference value. NASA counterpart of peer-reviewed formal professional papers but has less stringent limitations on manuscript length and extent of graphic presentations.

- TECHNICAL MEMORANDUM. Scientific and technical findings that are preliminary or of specialized interest, e.g., quick release reports, working papers, and bibliographies that contain minimal annotation. Does not contain extensive analysis.

- CONTRACTOR REPORT. Scientific and technical findings by NASA-sponsored contractors and grantees.
- CONFERENCE PUBLICATION. Collected papers from scientific and technical conferences, symposia, seminars, or other meetings sponsored or cosponsored by NASA.

- SPECIAL PUBLICATION. Scientific, technical, or historical information from NASA programs, projects, and missions, often concerned with subjects having substantial public interest.

- TECHNICAL TRANSLATION. Englishlanguage translations of foreign scientific and technical material pertinent to NASA's mission.

Specialized services also include creating custom thesauri, building customized databases, organizing and publishing research results.

For more information about the NASA STI program, see the following:

- Access the NASA STI program home page at http://www.sti.nasa.gov

- E-mail your question via the Internet to help@ sti.nasa.gov

- Fax your question to the NASA STI Help Desk at $443-757-5803$

- Telephone the NASA STI Help Desk at 443-757-5802

- Write to: NASA Center for AeroSpace Information (CASI) 7115 Standard Drive Hanover, MD 21076-1320 
NASA/TM-2010-216902

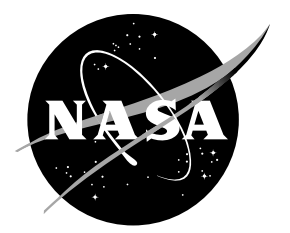

\section{Polarization Dependent Coupling of Whispering Gallery Modes in Microspheres}

G. Adamovsky and S. Wrbanek

Glenn Research Center, Cleveland, Ohio

B. Floyd

Sierra Lobo Incorporated, Cleveland, Ohio

M. Crotty

Glenn Research Center, Cleveland, Ohio

Prepared for the

Photonics North 2010

cosponsored by the Ontario Photonics Industry Network and Canadian Photonics Consortium Niagara Falls, Ontario, Canada, June 1-3, 2010

National Aeronautics and

Space Administration

Glenn Research Center

Cleveland, Ohio 44135 


\section{Acknowledgments}

The work has been supported by the Integrated Vehicle Health Management (IVHM) Project of the NASA Aviation Safety Program. M. Crotty also wishes to acknowledge the support of the NASA Undergraduate Student Research Program and NASA personnel involved in managing, organizing, and implementing the program at the Glenn Research Center.

Level of Review: This material has been technically reviewed by technical management.

Available from

NASA Center for Aerospace Information 7115 Standard Drive

Hanover, MD 21076-1320
National Technical Information Service 5301 Shawnee Road Alexandria, VA 22312

Available electronically at http://gltrs.grc.nasa.gov 


\title{
Polarization Dependent Coupling of Whispering Gallery Modes in Microspheres
}

\author{
G. Adamovsky and S. Wrbanek \\ National Aeronautics and Space Administration \\ Glenn Research Center \\ Cleveland, Ohio 44135 \\ B. Floyd \\ Sierra Lobo Incorporated \\ Cleveland, Ohio 44135 \\ M. Crotty ${ }^{1}$ \\ National Aeronautics and Space Administration \\ Glenn Research Center \\ Cleveland, Ohio 44135
}

\begin{abstract}
Two sets of resonances in glass microspheres attached to a standard communication-grade single-mode optical fiber have been observed. It has been found that the strength of the resonances depends strongly on the polarization of the coupled light. Furthermore, the position of the resonances in the wavelength domain depends on the polarization of light in the optical fiber with maximum magnitudes shifted by approximately $45^{\circ}$.

\subsection{Introduction}

The field of electromagnetic wave propagation is a well developed branch of physics and various physical models that have been supported by appropriate mathematical formulations (Refs. 1 to 3). That includes propagation of optical field in waveguides including optical fibers.

In recent years, that area of physics has received further attention partially owing to the advances in micro- and nano-optics. Specifically, with the advent of a phenomenon called morphology-dependent resonances or whispering gallery modes in dielectric resonant cavities like spheres and cylinders, optical waveguides have been used to deliver the optical field to the cavities (Ref. 4). The resonances observed and reported have been, in most cases, explained only in terms of properties of the resonant cavities and the environment.

The present paper documents our efforts to demonstrate and explain some effects of polarization of the incident light propagating in an optical fiber on the resonances triggered by coupling that light into microspheres.
\end{abstract}

\subsection{Theoretical}

In this work we deliver light to the microsphere using an optical fiber, which is a dielectric waveguide. The theory of wave propagation in cylindrical dielectric waveguides (Refs. 5 and 6) teaches that, from the formal solutions of Maxwell equations in cylindrical coordinates using matching boundary conditions on the core-cladding interface, two sets of solutions designated as the $E H$ and $H E$ modes could be extracted. Each of these two sets of modes by itself is a family of a sequence of modes defined by the parameter $l$. These sets,

${ }^{1}$ NASA Glenn Research Center, USRP Summer Intern. 
designated as $E H_{l m}$ and $H E_{l m}$ modes, are called hybrid modes, and have contributions from both $E_{z}$ and $H_{z}$ components. The relative contributions of $E_{z}$ and $H_{z}$ components to a transverse component of the field determines the designation of these hybrid modes. Furthermore, if $l=0$, we arrive at a special case when the field components of the modes are radially symmetric and the modes have nonvanishing fields components $H_{r}, H_{z}, E_{\phi}$ associated with $T E$ for one set of modes and $E_{r}, E_{z}, H_{\phi}$ associated with the $T M$ modes for the other set. These sets of modes are $T E_{0 m}$ and $T M_{0 m}$ modes, respectively. Analyses done by Yariv (Ref. 6) have also shown that $H E_{11}$ does not have a cutoff frequency and the mode propagates in a fiber with any diameter. It also means that the mode $H E_{11}$ propagates at any wavelength.

Each propagating mode has its own propagation constant $\beta$, which is usually expressed as a function of the normalized frequency $V$. Furthermore, $\beta=n k_{0}$, where $n$ the effective mode index or the ratio of the speed of light in vacuum to the mode phase velocity. The value of the normalized frequency determines the number of modes the optical fiber can propagate. If $V<2.405$, then only one mode, $H E_{11}$, could propagate and the fiber would be a single-mode fiber.

The mathematical treatment of mode propagation in a cylindrical fiber is significantly simplified with the introduction of the weakly guiding modes approximation (Ref. 7). It follows from the approximation that the longitudinal components of the propagating fields are small compared with the transverse ones. Furthermore, the modes are considered to be linearly polarized in the transverse plane (Ref. 8). Such modes are called linearly polarized and designated as $L P_{l m}$ modes. In the $L P$ modes the transverse fields inside the core are presented as products of Bessel functions in the radial direction and trigonometric functions sines and cosines in the angular direction (Refs. 9 and 10). The subscript $l$ represents the $l$ th-order Bessel function corresponding to the cutoff condition of the mode and $m$ is the number of successive zeros in that Bessel function. In other words, the subscript $l$ gives the number of angular nodes or azimuthal periodicity in the field distribution and the subscript $m$ gives the number of radial nodes.

Each of the $L P_{l m}$ modes has also two mutually orthogonal components associated with $E$ and $H$ components of the electromagnetic field. Thus, modes with $l=0$ have two orthogonal states of polarization and "donut shaped" distributions of field intensities. Furthermore, the lowest order linearly polarized mode $L P_{01}$ includes the conventional lowest order mode $H e_{11}$.

The next linearly polarized mode, $L P_{11}$, is a combination of $H E_{21}, T M_{01}$, and $T E_{01}$ conventional modes. It can be constructed choosing $\sin (l \phi)$ or $\cos (l \phi)$ in the transverse angular distribution $(\varphi$ is the angular coordinate) of the field intensity and two orthogonal states of polarization. As a result, the $L P_{11}$ mode has four possible distributions with $90^{\circ}$ symmetry in the circumferential (angular) $\phi$ direction. The $L P_{11}$ mode occurs when $2.405 \leq V<3.832$. As the value of $V$ increases even higher order modes become guided. Eventually we will have a multimode fiber with a large number of modes propagating through it.

When the propagating $L P$ modes reach a microsphere, they are trapped in the sphere and form whispering gallery modes - also known as morphology dependent resonances. Those resonances also occur in resonant cavities with shapes formed by bodies of revolution such as cylinders, ellipsoids, etc. Resonant cavities discriminate certain wavelengths by selectively insolating them. Geometry and dimensions of the cavity, material properties, and the environmental conditions are the main factors in determining the wavelengths.

Descriptions of optical processes in microspheres could be found elsewhere (Ref. 11). Owing to the dependency of resonances on geometric and material properties of microspheres, as well as the environment, such microspheres have been proposed as sensing structures for various applications including medical, chemical, and aerospace (Ref. 12).

\subsection{Experimental}

The basic apparatus to generate whispering gallery modes in microspheres has been already published (Ref. 11). It comprises a light source, usually a tunable semiconductor laser diode, a microsphere about $450 \mu \mathrm{m}$ in diameter and usually mounted on a stem for easy handling and manipulation, a waveguide to deliver light from the source to the microsphere, and a photodetector. For instance, Figure 1, adopted from 
Reference 12 , shows a schematics setup to generate optical resonances in a microsphere via a side-coupled optical fiber.

The operating wavelength of the laser is between 1290 and $1330 \mathrm{~nm}$, and the output power is about $20 \mathrm{~mW}$. The laser operates in a tunable mode and emits light whose wavelength varies in time. This is achieved by sending a monotonically changing current through the laser diode junction. In response, the wavelength changes accordingly. The light generated by the laser is coupled into an optical fiber. The microsphere is placed close to the fiber in such a manner that light at certain wavelengths is coupled into the microsphere. The photodetector detects the light that passes through the fiber. When the microsphere is absent, the photodetector displays a continuing spectrum across all wavelengths emitted by the laser over the given period of time. However, the microsphere extracts certain wavelengths, and signals at these wavelengths are not being carried toward the photodetector. The result appears as sharp decreases in light intensity at wavelengths that couple into the sphere.

To obtain stable operation of the laser, the process of changing current through a laser junction is accompanied by keeping the junction temperature constant. However, the resultant tuning range of the laser diode does not exceed $0.6 \mathrm{~nm}$. This range has been often found insufficient to observe the resonances. To increase the tuning range, the process of changing current is combined with changing the constant temperature ranges (Ref. 12).

Various techniques to deliver light to the microsphere via an optical fiber have been proposed (Ref. 13). One of the most efficient arrangements to couple light into a microsphere using optical fibers involves a device called either fiber half-block or half-coupler (Ref. 14). The half-coupler is constructed by cementing a piece of fiber in a glass block and polishing a flat section on the fiber cylindrical surface. The polishing removes part of the cladding, therefore a microsphere placed on the flat section is located closer to the core.

Figure 2 shows our experimental setup used to demonstrate the effects of using a fiber to deliver light to a microsphere. It has a tunable laser, a laser controller, a half-coupler with a microsphere positioned on the top of it, and an optical fiber. Electrical current from the laser controller is applied to a tunable laser. The current is time dependent and, as a result, the wavelength of light emitted by the laser has an identical time dependency. The light is coupled into a commercial single-mode fiber with parameters described in the following paragraph. Also, a linear polarizer is incorporated in the path of the light. This is done by putting the polarizer between two fibers as shown in Figure 2 and aligning the fibers to achieve the maximum coupling of light from one fiber to another through the polarizer.

The fiber used in the setup is a commercial-grade single-mode fiber specified for 1300/1550 nm wavelengths. The fiber is a standard in the communication industry and has the following parameters: the core diameter $8.2 \mu \mathrm{m}$, refractive index difference $\Delta=0.36$ percent, and the effective index of refraction $n$ is 1.4677 and 1.4682 for 1310 and $1550 \mathrm{~nm}$ wavelength, respectively (Ref. 15). Calculations show that the corresponding normalized frequency $V$, a parameter defined earlier, is 2.449 and 2.071 for those respective wavelengths. Thus, the parameter $V$ for the wavelength of $1310 \mathrm{~nm}$ and below is above the normalized cutoff frequency of 2.405. Technically, we do not have a single-mode operation anymore and rather are dealing with a two-mode case. The presence of the second mode does not practically change the propagating properties of the fiber because that mode propagates very close to the core-cladding interface and carries a very insignificant amount of power.

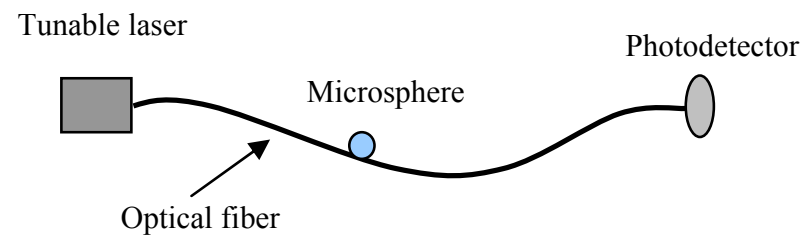

Figure 1.-Schematic setup to generate optical resonances in a microsphere by side-coupled optical fiber. [Adopted from Ref. 12] 


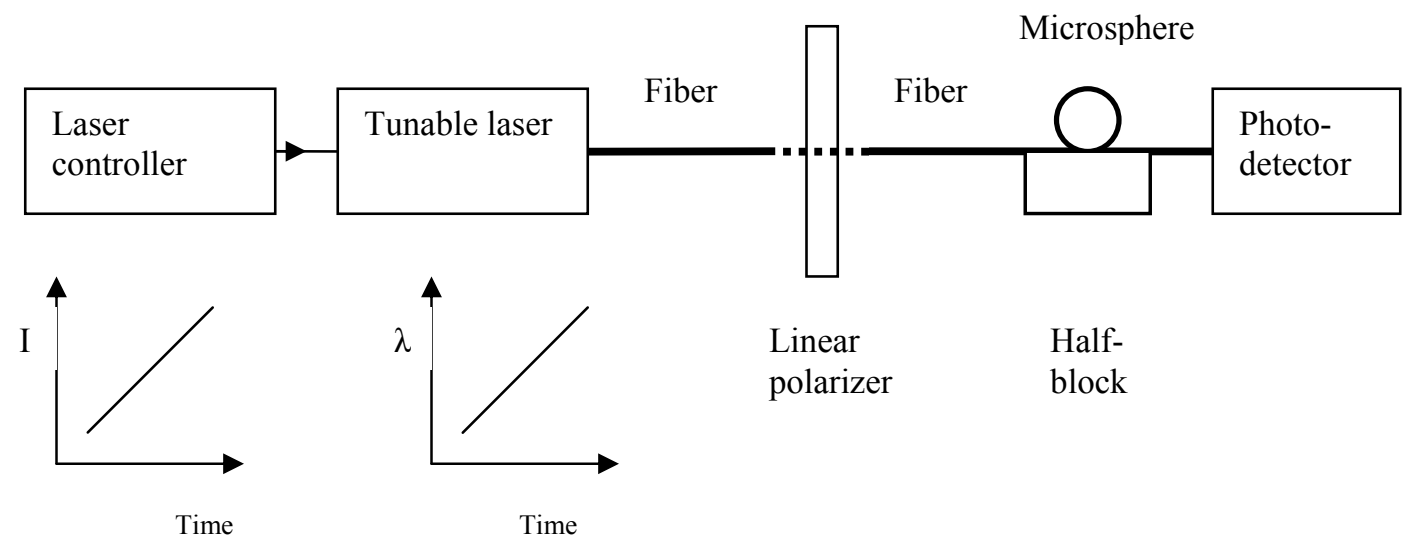

Figure 2.-Diagram of the experimental setup.

TABLE 1.-TABULATED CALIBRATION DATA FOR THE LASER DIODE

\begin{tabular}{|c|c|c|c|c|c|}
\hline $\begin{array}{c}\text { Current, } \\
\mathrm{mA}\end{array}$ & $\begin{array}{c}\text { Temperature, } \\
5{ }^{\circ} \mathrm{C} \\
\text { Wavelength, } \\
\text { nm }\end{array}$ & $\begin{array}{c}\text { Temperature, } \\
10{ }^{\circ} \mathrm{C} \\
\text { Wavelength, } \\
\text { nm }\end{array}$ & $\begin{array}{c}\text { Temperature, } \\
15{ }^{\circ} \mathrm{C} \\
\text { Wavelength, } \\
\text { nm }\end{array}$ & $\begin{array}{c}\text { Temperature, } \\
20{ }^{\circ} \mathrm{C} \\
\text { Wavelength, } \\
\text { nm }\end{array}$ & $\begin{array}{c}\text { Temperature, } \\
25{ }^{\circ} \mathrm{C} \\
\text { Wavelength, } \\
\text { nm }\end{array}$ \\
\hline 20 & 1303.548 & $\mathbf{1 3 0 4 . 0 2 3}$ & 1304.5 & 1304.978 & 1305.458 \\
30 & $\mathbf{1 3 0 3 . 5 7 6}$ & $\mathbf{1 3 0 4 . 0 5 1}$ & $\mathbf{1 3 0 4 . 5 1 5}$ & 1304.993 & 1305.49 \\
40 & $\mathbf{1 3 0 3 . 6 0 7}$ & $\mathbf{1 3 0 4 . 0 8 4}$ & $\mathbf{1 3 0 4 . 5 3}$ & $\mathbf{1 3 0 5 . 0 1}$ & $\mathbf{1 3 0 5 . 5 0 9}$ \\
50 & $\mathbf{1 3 0 3 . 6 4 1}$ & $\mathbf{1 3 0 4 . 1 0 1}$ & $\mathbf{1 3 0 4 . 5 6 3}$ & $\mathbf{1 3 0 5 . 0 4 4}$ & $\mathbf{1 3 0 5 . 5 2 7}$ \\
60 & $\mathbf{1 3 0 3 . 6 7 8}$ & $\mathbf{1 3 0 4 . 1 1 9}$ & $\mathbf{1 3 0 4 . 6}$ & $\mathbf{1 3 0 5 . 0 8 2}$ & $\mathbf{1 3 0 5 . 5 6 7}$ \\
70 & $\mathbf{1 3 0 3 . 7 1 7}$ & $\mathbf{1 3 0 4 . 1 5 7}$ & $\mathbf{1 3 0 4 . 6 3 9}$ & $\mathbf{1 3 0 5 . 1 2 4}$ & $\mathbf{1 3 0 5 . 6 0 9}$ \\
80 & $\mathbf{1 3 0 3 . 7 6}$ & $\mathbf{1 3 0 4 . 1 9 8}$ & $\mathbf{1 3 0 4 . 6 8 2}$ & $\mathbf{1 3 0 5 . 1 6 8}$ & $\mathbf{1 3 0 5 . 6 5 6}$ \\
90 & $\mathbf{1 3 0 3 . 8 0 6}$ & $\mathbf{1 3 0 4 . 2 4 2}$ & $\mathbf{1 3 0 4 . 7 2 8}$ & $\mathbf{1 3 0 5 . 2 1 6}$ & $\mathbf{1 3 0 5 . 7 0 5}$ \\
100 & $\mathbf{1 3 0 3 . 8 5 5}$ & $\mathbf{1 3 0 4 . 2 9}$ & $\mathbf{1 3 0 4 . 7 7 8}$ & $\mathbf{1 3 0 5 . 2 6 7}$ & $\mathbf{1 3 0 5 . 7 5 8}$ \\
110 & $\mathbf{1 3 0 3 . 9 0 8}$ & $\mathbf{1 3 0 4 . 3 4 1}$ & $\mathbf{1 3 0 4 . 8 3 1}$ & $\mathbf{1 3 0 5 . 3 2 1}$ & $\mathbf{1 3 0 5 . 8 1 4}$ \\
120 & $\mathbf{1 3 0 3 . 9 6 3}$ & $\mathbf{1 3 0 4 . 3 9 5}$ & $\mathbf{1 3 0 4 . 8 8 6}$ & $\mathbf{1 3 0 5 . 3 7 9}$ & $\mathbf{1 3 0 5 . 8 7 4}$ \\
125 & $\mathbf{1 3 0 3 . 9 9 2}$ & $\mathbf{1 3 0 4 . 4 5 2}$ & $\mathbf{1 3 0 4 . 9 4 5}$ & $\mathbf{1 3 0 5 . 4 4}$ & $\mathbf{1 3 0 5 . 9 3 6}$ \\
130 & $\mathbf{1 3 0 4 . 0 2 1}$ & $\mathbf{1 3 0 4 . 5 1 2}$ & $\mathbf{1 3 0 5 . 0 0 7}$ & $\mathbf{1 3 0 5 . 5 0 3}$ & $\mathbf{1 3 0 6 . 0 0 2}$ \\
140 & 1304.099 & 1304.575 & 1305.073 & 1305.571 & 1306.071 \\
\hline
\end{tabular}

Prior to starting the experiment, a calibration procedure is performed to assure the continuity of the laser performance at different temperatures and different currents. We used five fixed temperatures regimes, 5, 10, 15,20 , and $25^{\circ} \mathrm{C}$, and changed the current at each temperature. The calibration involved finding the wavelength-current relationship at every fixed laser diode temperature and doing a continuous mapping. Results of these measurements are presented in Table 1.

\subsection{Results and Discussion}

The experiment involved scanning the laser wavelength through all five temperature segments and observing and recording resonances at each temperature segment separately. The experiment consisted of two parts. The first part was conducted without the polarization filter to observe the resonances that occurred over the entire tuning range of the laser diode at all temperature regimes. Figures 3(a) to (e) show resonances obtained during the first part of the experiment over five individual temperature segments. 


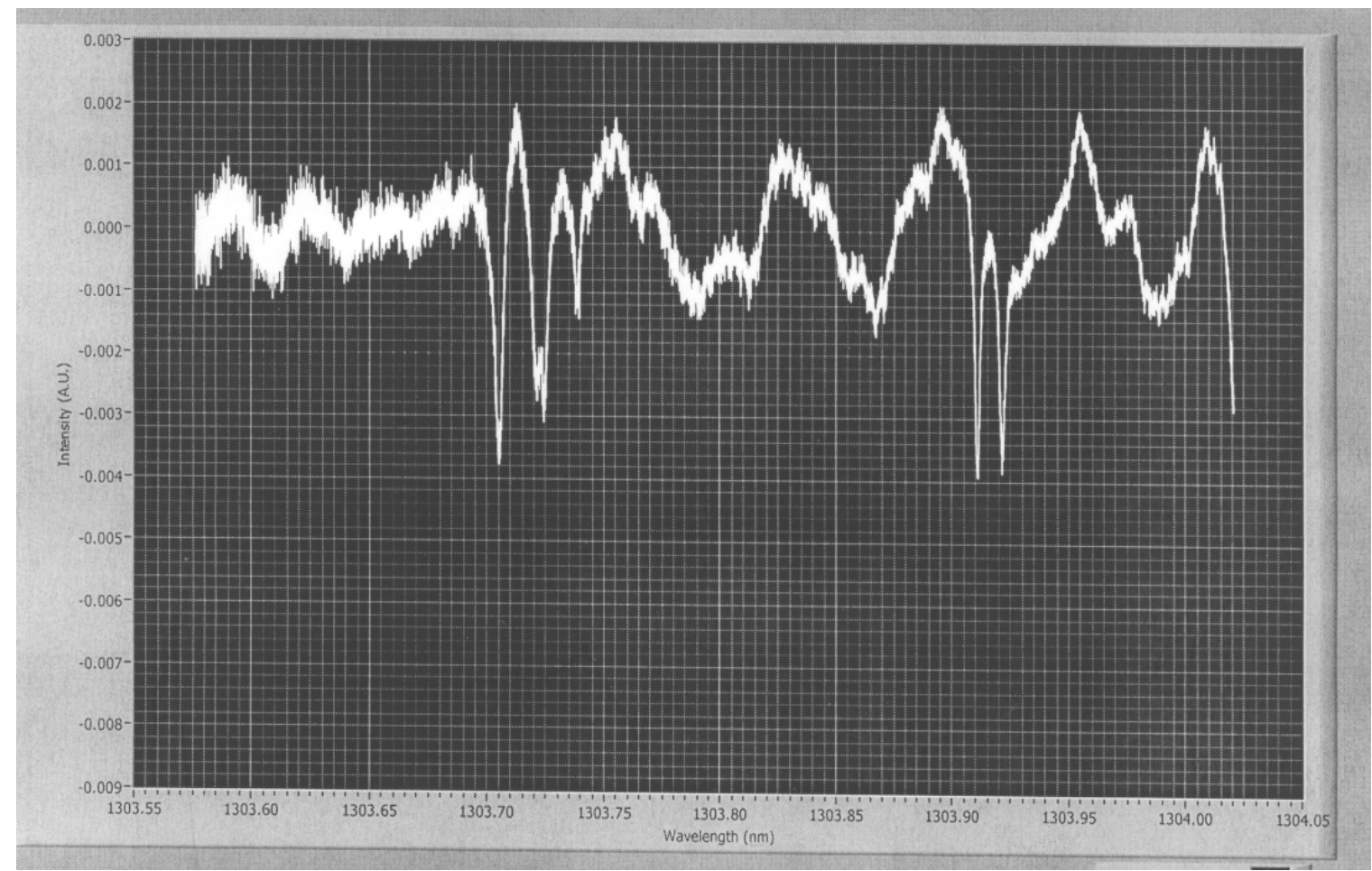

a)

Figure 3.-Resonances obtained without the polarizer for the laser diode temperatures: a) $5^{\circ} \mathrm{C}$; b) $10^{\circ} \mathrm{C}$; c) $15^{\circ} \mathrm{C}$; d) $20^{\circ} \mathrm{C}$; e) $25^{\circ} \mathrm{C}$.

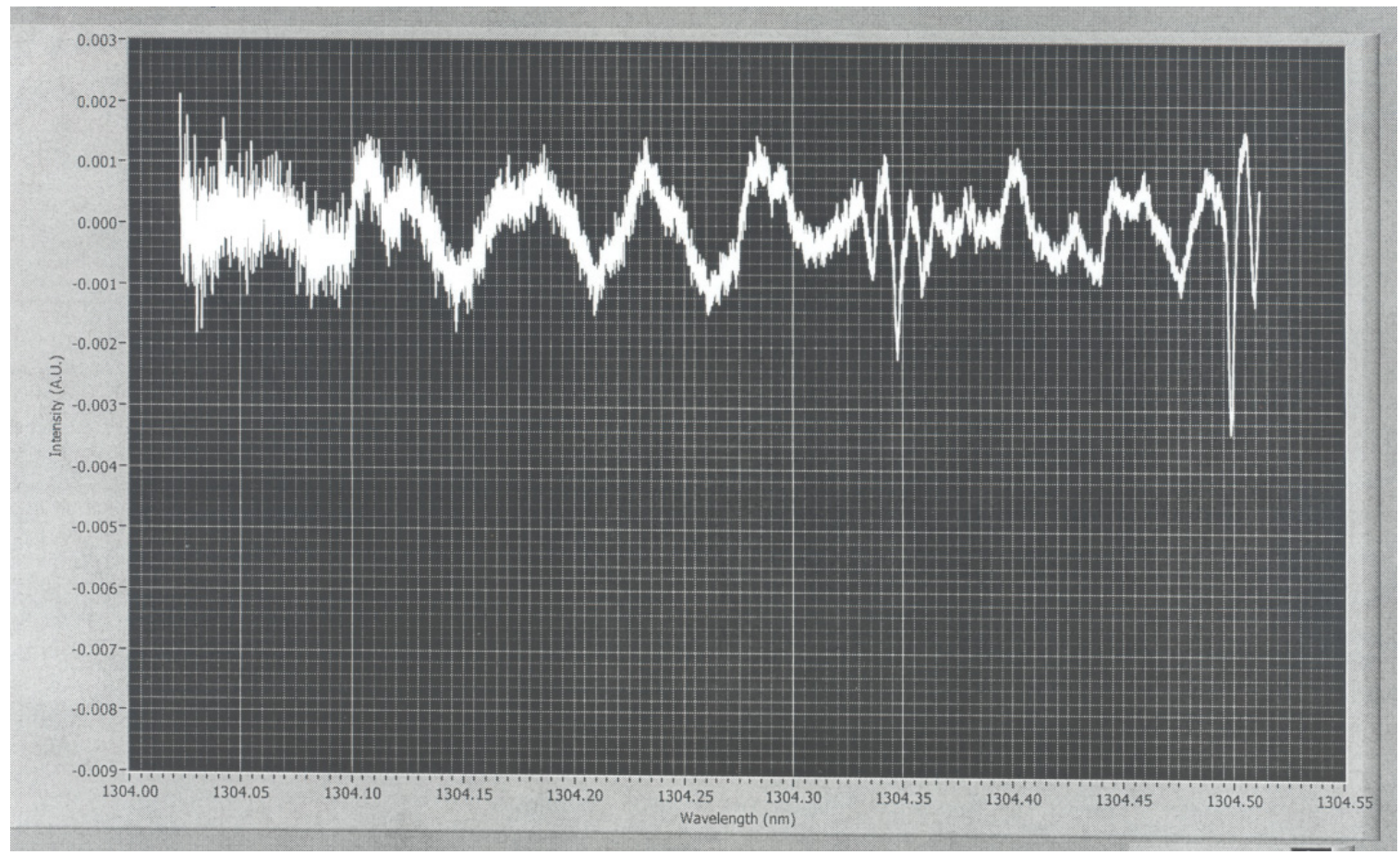

b)

Figure 3.-Continued. 


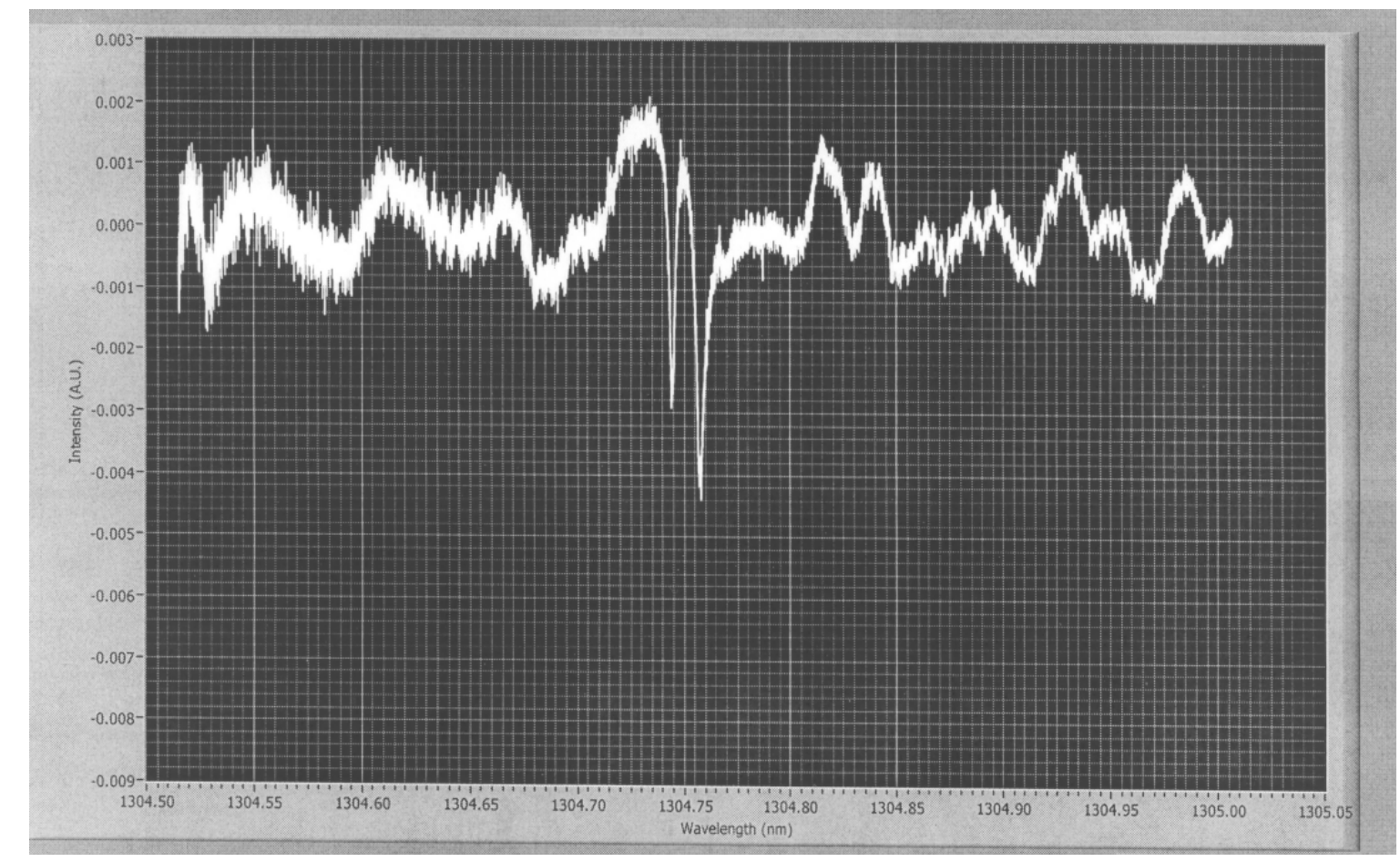

c)

Figure 3.-Continued.

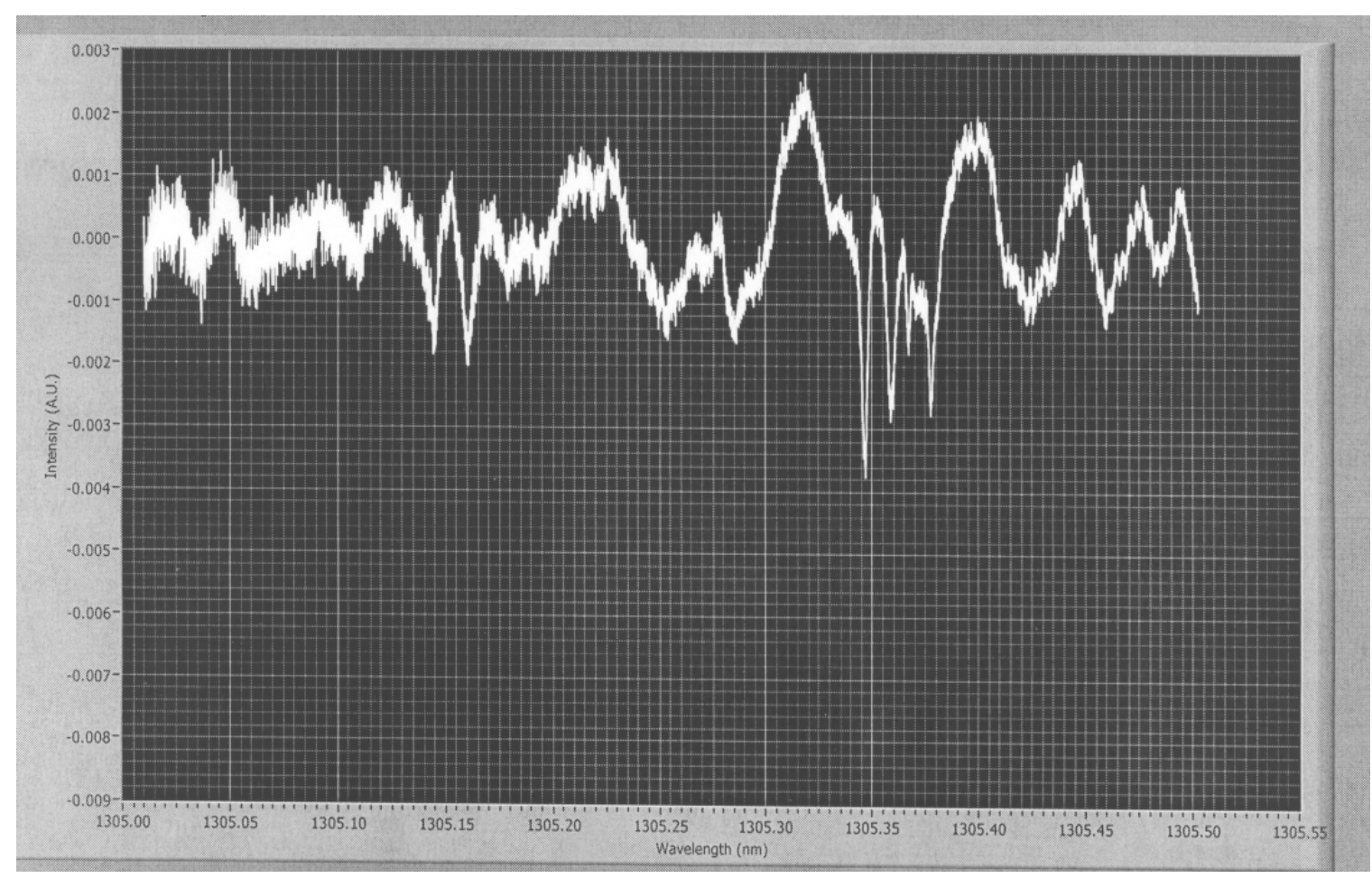

d)

Figure 3.-Continued. 


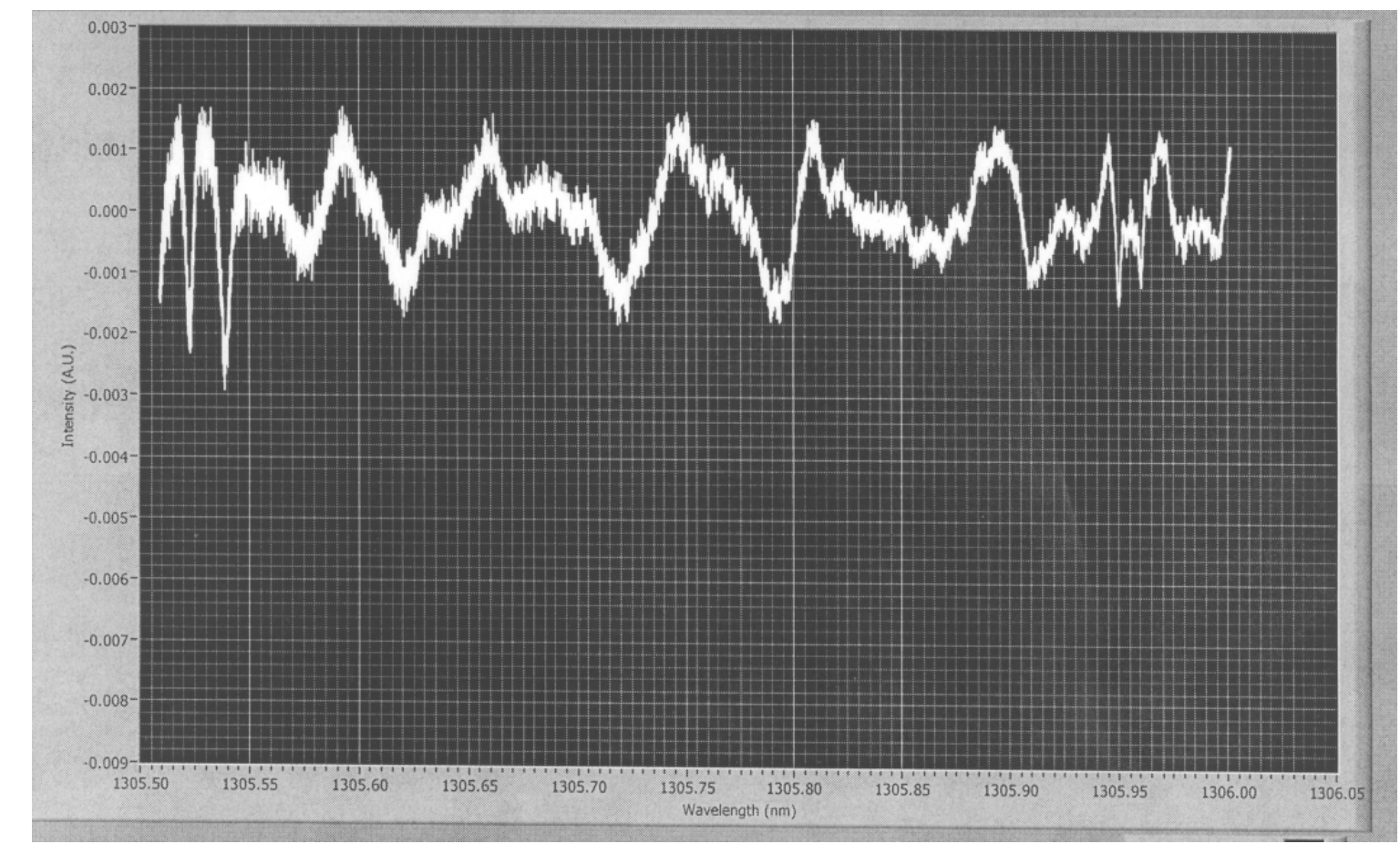

e)

Figure 3.-Concluded.

The second part of the experiment was conducted with the polarizer inserted in the gap between the fiber from the laser diode and the fiber to the microsphere as is shown in Figure 2. The polarizer was placed in a special mount that permitted rotation of the polarizer around its optical axis. The mount has a dial with 360 angular gradations separated by 1 angular degree. The dial enables an accurate rotation of the polarizer.

In the process of conducting the second part of experiment we set the temperature of the laser at a certain fixed temperature and rotated the polarizer with a $10^{\circ}$ angular increment. At each angular position of the polarizer we conducted the wavelength scan over the appropriate wavelength range and recorded the resonances. That process was repeated at all five temperature segments. The recorded resonances for the first temperature segment, $5^{\circ} \mathrm{C}$, are shown in Figure 4. The resonances are grouped in columns with four angular positions per row. The resonances in each row are obtained by rotating the polarization filter by $90^{\circ}$ and they are almost identical. The columns show resonances obtained under incremental change in the angular position of the filter.

Owing to the clear $90^{\circ}$ symmetry in resonances displayed in Figure 4, the next figure (Fig. 5) shows those resonances selected from the complete set in Figure 4 that occurred within the first polarization quadrant.

Similar sets of resonances were also obtained with the laser diode thermally stabilized at 15,20 , and $25^{\circ} \mathrm{C}$. In each position of the polarizer we conducted the wavelength scan over the entire tuning range over all five temperature segments. Resonances over the entire tuning range for four angular positions of the polarizer, $0^{\circ}, 60^{\circ}, 120^{\circ}$, and $180^{\circ}$, are shown in Figure 6 .

The columns in Figure 6 represent resonances observed over the entire tuning range of the laser for the selected angular positions of the polarizer. The rows in the figure represent resonances at the selected angular positions obtained at a given stabilized temperature of the laser. 

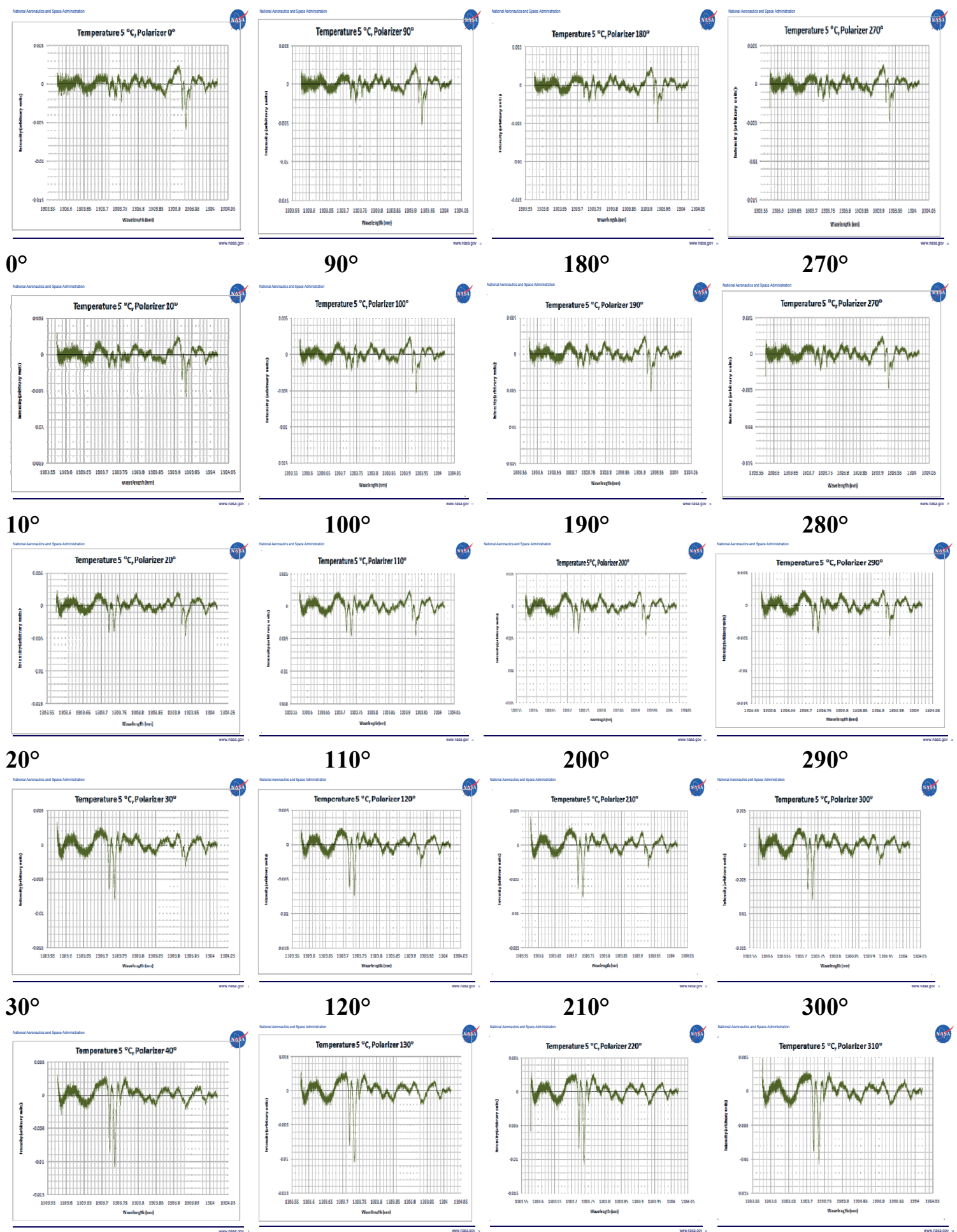

$40^{\circ}$
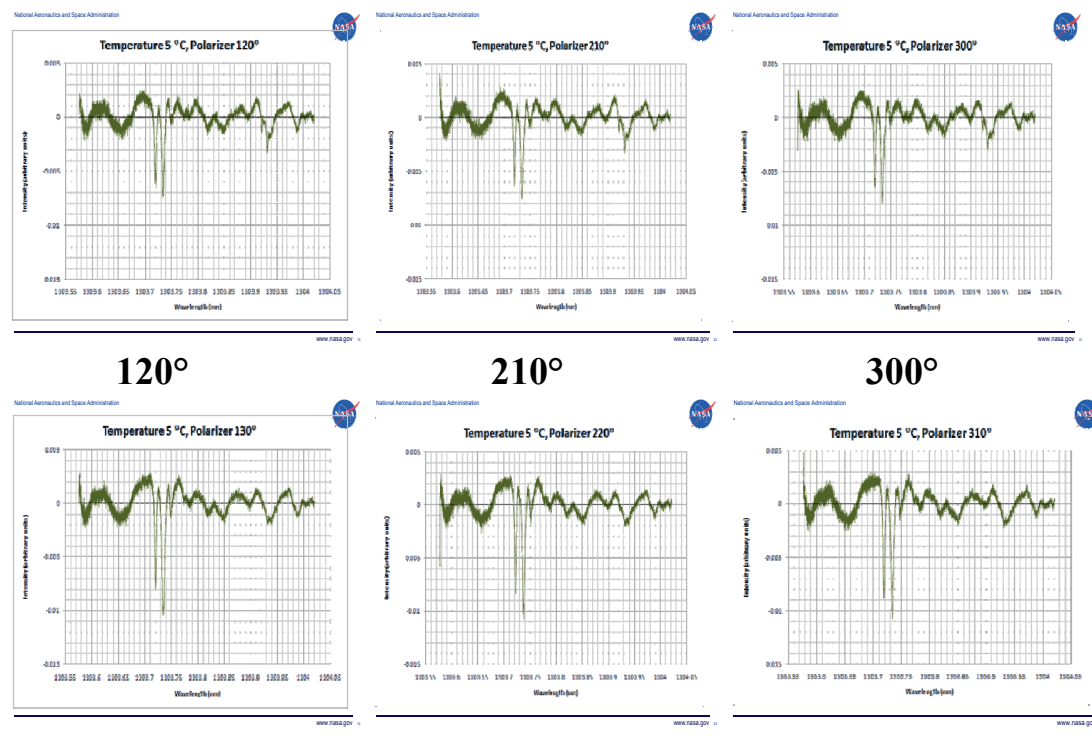

$130^{\circ}$
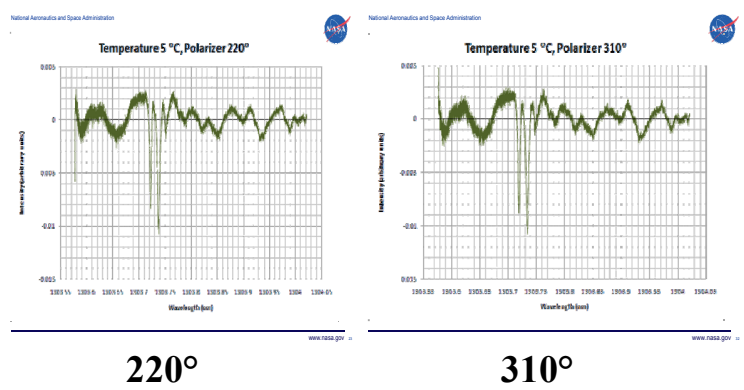

Figure 4.-Resonances obtained with the laser diode thermally stabilized at $5^{\circ} \mathrm{C}$ and the polarizer rotated with a $10^{\circ}$ increment. 


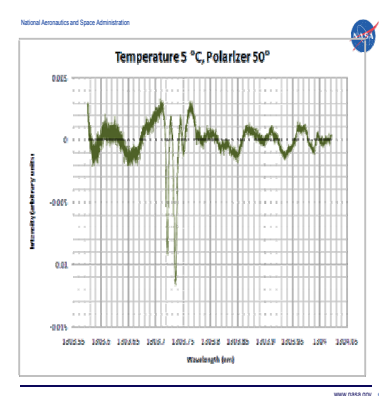

$50^{\circ}$

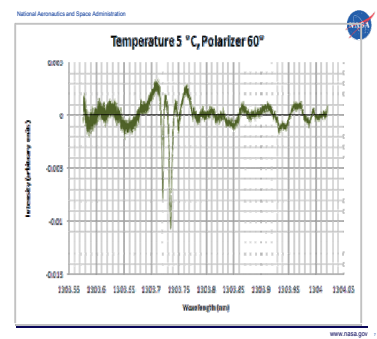

$60^{\circ}$
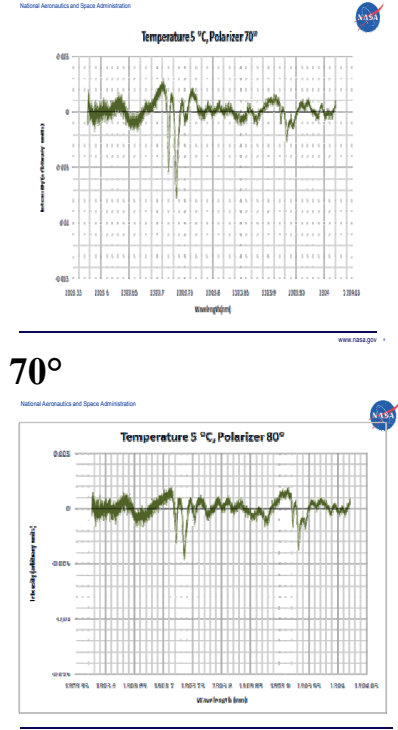

$80^{\circ}$

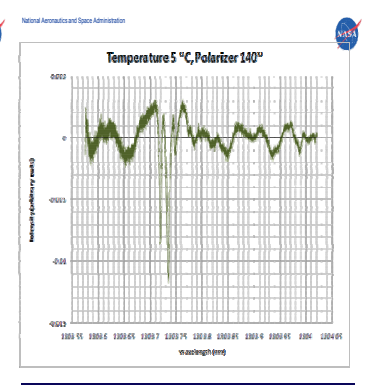

$140^{\circ}$
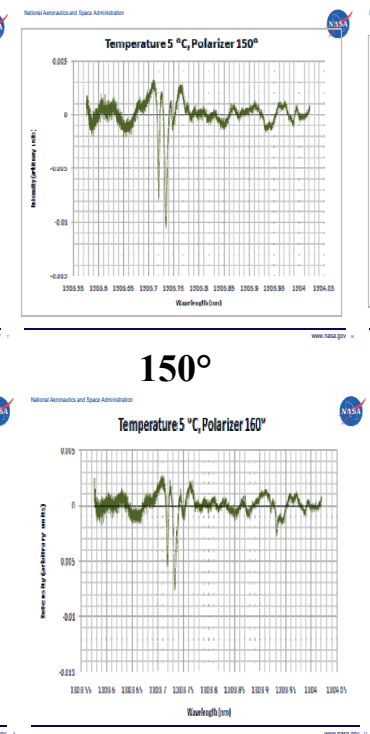

$160^{\circ}$

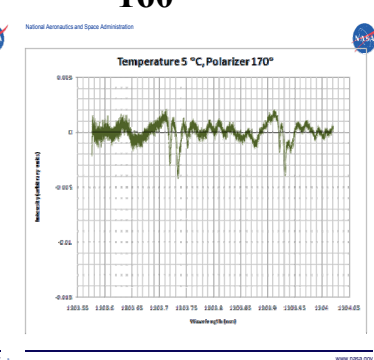

$170^{\circ}$

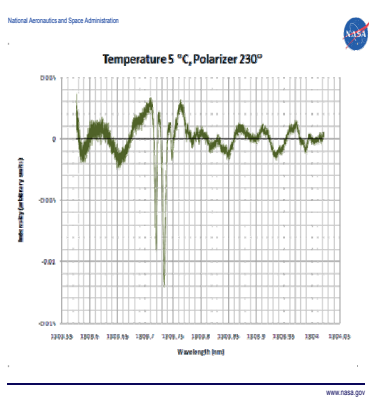

$230^{\circ}$

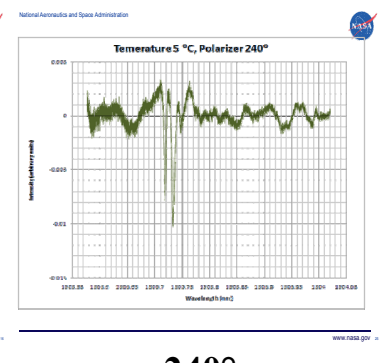

$240^{\circ}$
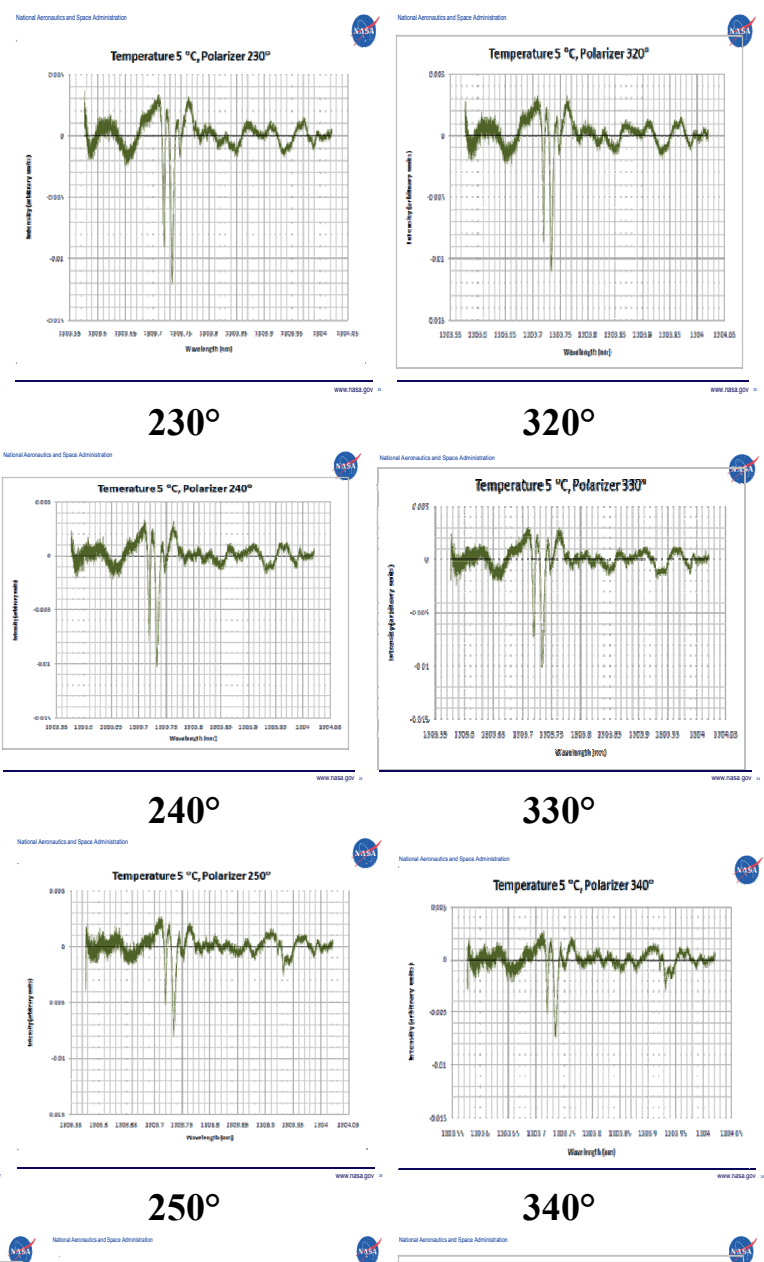

$330^{\circ}$

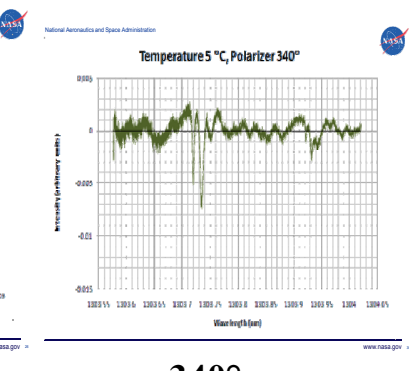

$340^{\circ}$

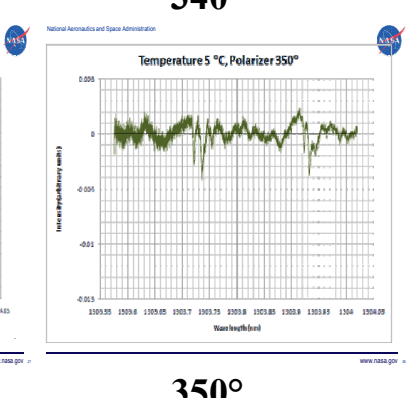

$350^{\circ}$

Figure 4.-Concluded. 


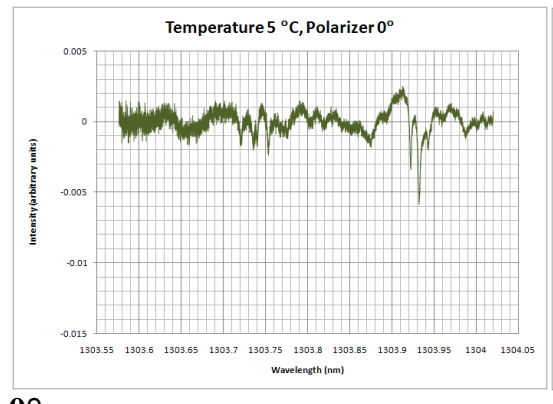

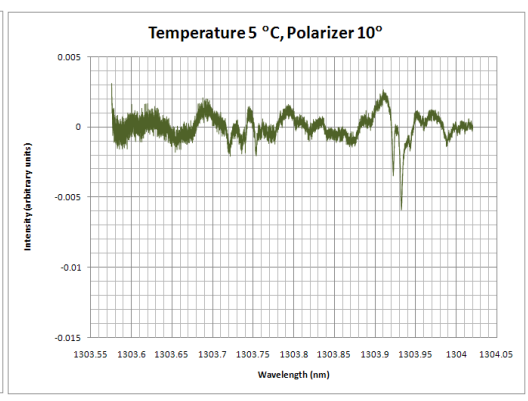

$10^{\circ}$

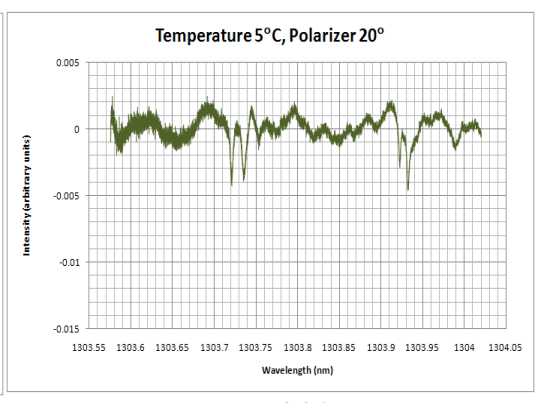

$20^{\circ}$

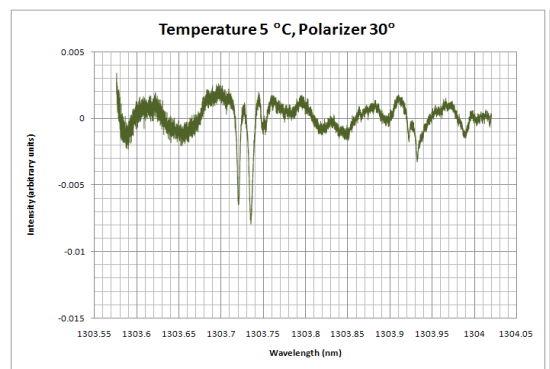

$30^{\circ}$

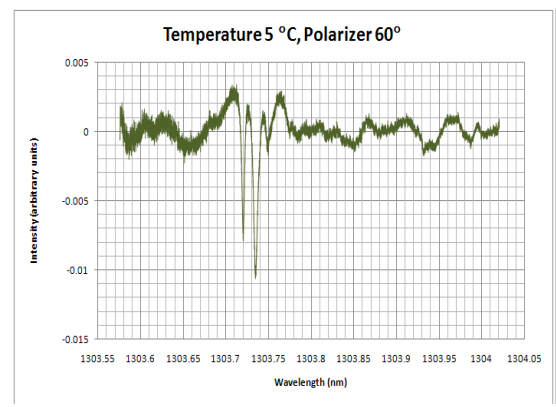

$60^{\circ}$

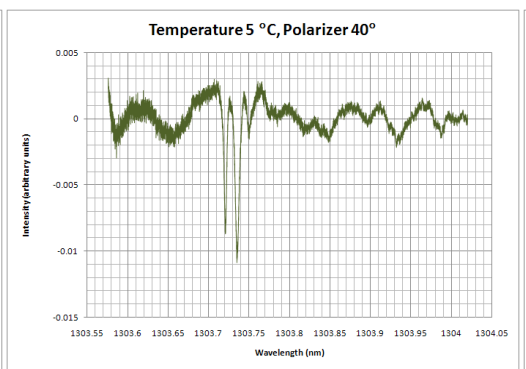

$40^{\circ}$

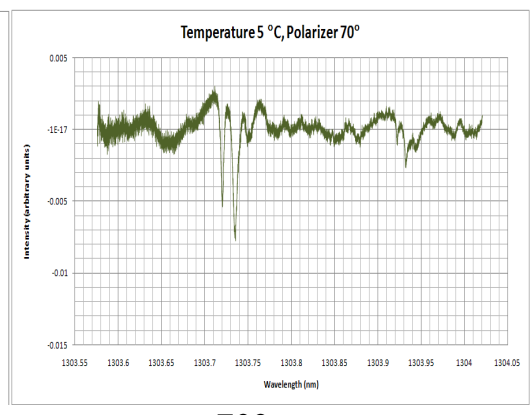

$70^{\circ}$

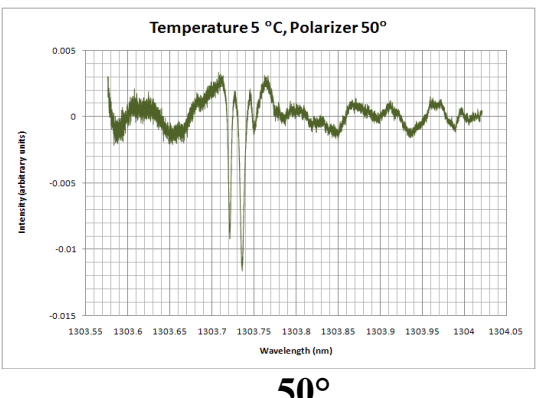

$50^{\circ}$

Figure 5.--Resonances from the set shown in Figure 4 that occurred within the first quadrant. 


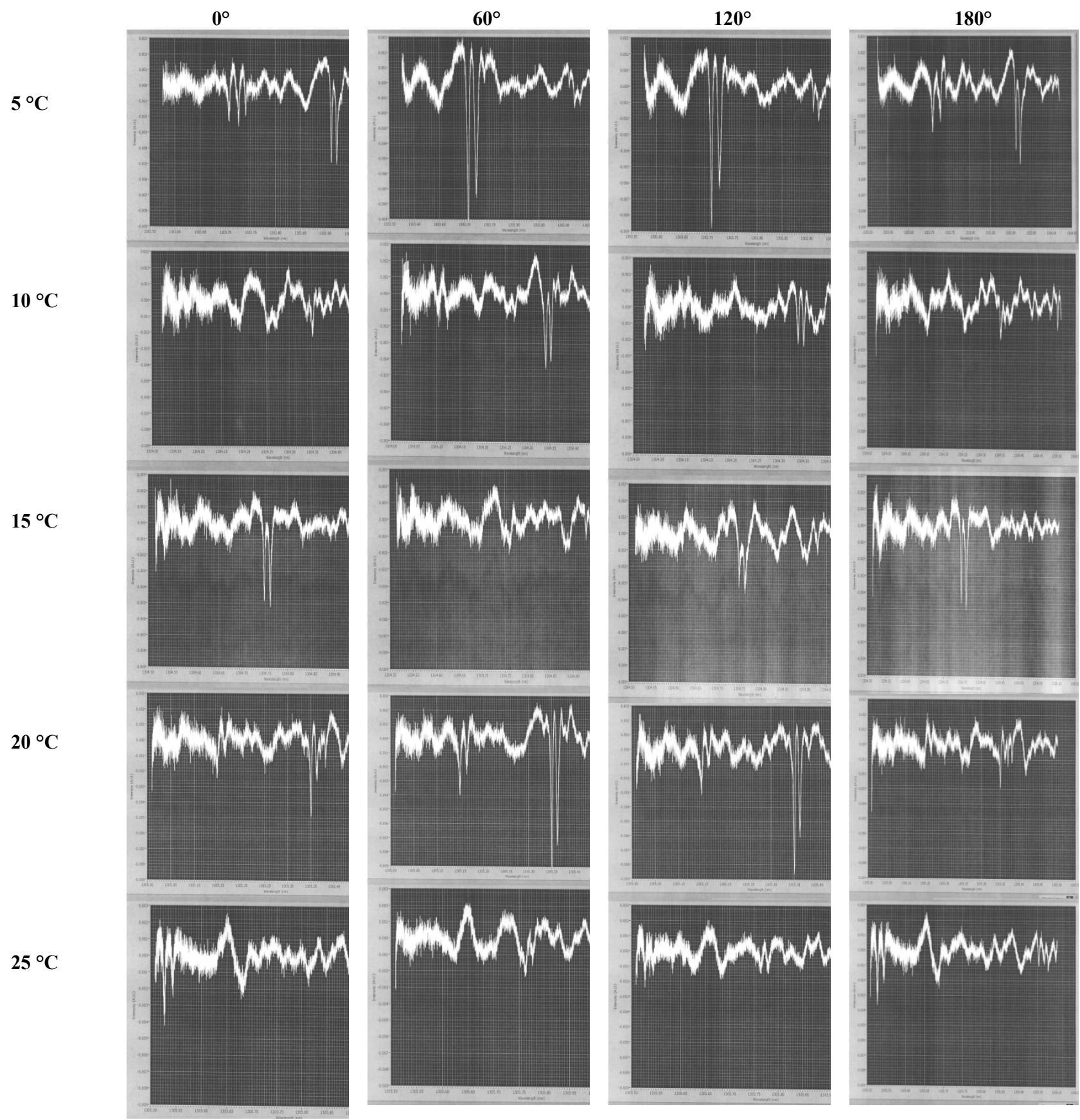

Figure 6.- Resonances over the entire tuning range for four angular positions of the polarizer.

\subsection{Conclusions}

The patterns presented in Figures 4 and 5 clearly show a presence of two sets of resonances. The strength of the resonances varies with the angular polarization and each of the sets has a $90^{\circ}$ angular periodicity. Moreover, the sets appear to have angular positions of the polarizer that correspond the maximum strengths of the resonances shifted by, what could be estimated as, about $45^{\circ}$. 
The behavior of the resonances is characteristic of the behavior of two linearly polarized modes, $L P_{01}$ and $L P_{11}$. The $90^{\circ}$ symmetry in the resonance patterns could be explained by the existence of two mutually orthogonal components associated with $E$ and $H$ components of the electromagnetic field. The fact that the maxima in the intensities for resultant resonances in the microsphere do not occur at the same angle could be explained by the differences in the electric (and magnetic) field amplitude profiles for $L P_{01}$ and $L P_{11}$ modes.

We have demonstrated experimentally that the strength and wavelength of whispering gallery resonances in microspheres depends on the polarization of the incident light. We also demonstrated appearance of two sets of resonances that could be attributed to the fact that at our operating wavelengths the fiber used was not single-mode and two linearly polarized modes, $L P_{01}$ and $L P_{11}$, were present. The $L P_{11}$ mode propagates close to the core - cladding interface and is also coupled into the microsphere.

The setup that we presented and arrangement of the experiment demonstrated polarization dependent coupling of whispering gallery modes in microspheres. The strength and location of these modes in wavelength domain appeared to be in agreement with the two lowest linearly polarized modes propagating in the fiber, $L P_{01}$ and $L P_{11}$.

\section{References}

1. Collin, R.E.: Field Theory of Guided Waves. Second ed., IEEE Press, New York, NY, 1990.

2. Balanis, C.A.: Advanced Engineering Electromagnetics. John Wiley \& Sons, New York, NY, 1989.

3. Ishimary, A.: Electromagnetic Wave Propagation, Radiation, and Scattering. Prentice Hall, Englewood Cliffs, NJ, 1991.

4. Arnold, S.: Microspheres, Photonic Atoms and the Physics of Nothing. American Scientist, vol. 89, no. 5, 2001, pp. 414-421.

5. Marcuse, D.: Light Transmission Optics. Second ed., ch. 8, Van Nostrand Reinhold Company, New York, NY, 1982.

6. Yariv, A.: Optical Electronics. Propagation of Optical Beams in Fibers, Third ed., ch. 3, CBS College Publishing, New York, NY, 1985, pp. 54-86.

7. Gloge, D.: Weakly Guiding Fibers. Appl. Opt., vol. 10, no. 10, 1971, pp. 2252-2258.

8. Jeunhomme, L.B.: Single-Mode Fiber Optics: Principles and Applications. Second ed., ch. 1, Optical Engineering Series, B.J. Thompson, ed., vol. 23, Marcel Dekker, New York, NY, 1990, pp. 1-59.

9. Gloge, D.: Propagation Effects in Optical Fibers. IEEE Trans. Microwave Theory Tech., MTT-23, no. 1, 1975, pp. 106-120.

10. Kumar D.; and Choudhury, P.K.: Introduction to Modes and Their Designation in Circular and Elliptical Fibers. Am. J. Phys., vol. 75, no. 6, 2007, pp. 546-551.

11. Chang, R.K.; and Campilla, A.J., eds.: Optical Processes in Microcavities, Advanced Series in Applied Physics, vol. 3, World Scientific Publishing Co., Singapore, 1996.

12. Adamovsky, G.; and Ötügen, V.: Morphology-Dependent Resonances and Their Applications to Sensing in Aerospace Environments. AIAA J. Aerospace Computing, Information, and Communication, JACIC, vol. 5, no. 10, 2008, pp. 409-424.

13. Little, B.E., et al.: Pedestal Antiresonant Reflecting Waveguides for Robust Coupling to Microsphere Resonators and for Microphotonic Circuits. Opt. Lett., vol. 25, no. 1, 2000, pp. 73-75.

14. Serpengüzel, A.; Arnold, S.; and Griffel, G.: Excitation of Resonances of Microspheres on an Optical Fiber. Opt. Let., vol. 20, no. 7, 1995, pp. 654-656.

15. Corning ${ }^{\circledR}$ Single-Mode Optical Fiber, Corning Inc., 2000.

http://cc.ee.ntu.edu.tw/ ypchiou/Photonic_Crystals/SMF28Fiber.pdf 


\begin{tabular}{|c|c|c|c|c|c|}
\hline \multicolumn{5}{|c|}{ REPORT DOCUMENTATION PAGE } & $\begin{array}{l}\text { Form Approved } \\
\text { OMB No. 0704-0188 }\end{array}$ \\
\hline \multicolumn{6}{|c|}{ 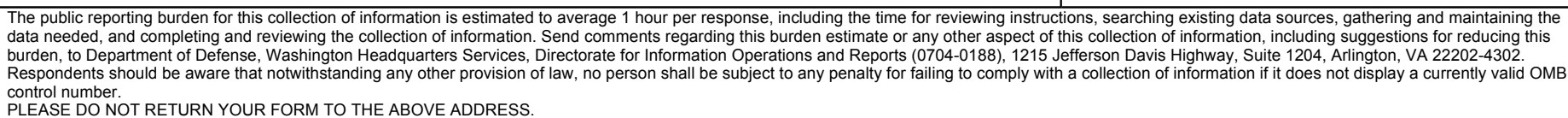 } \\
\hline \multicolumn{2}{|c|}{$\begin{array}{l}\text { 1. REPORT DATE (DD-MM-YYYY) } \\
01-11-2010\end{array}$} & \multicolumn{3}{|c|}{$\begin{array}{l}\text { 2. REPORT TYPE } \\
\text { Technical Memorandum }\end{array}$} & 3. DATES COVERED (From - To) \\
\hline \multirow{3}{*}{\multicolumn{5}{|c|}{$\begin{array}{l}\text { 4. TITLE AND SUBTITLE } \\
\text { Polarization Dependent Coupling of Whispering Gallery Modes in Microspheres }\end{array}$}} & 5a. CONTRACT NUMBER \\
\hline & & & & & 5b. GRANT NUMBER \\
\hline & & & & & 5c. PROGRAM ELEMENT NUMBER \\
\hline \multirow{3}{*}{\multicolumn{5}{|c|}{$\begin{array}{l}\text { 6. AUTHOR(S) } \\
\text { Adamovsky, G.; Wrbanek, S.; Floyd, B.; Crotty, M. }\end{array}$}} & 5d. PROJECT NUMBER \\
\hline & & & & & 5e. TASK NUMBER \\
\hline & & & & & $\begin{array}{l}\text { 5f. WORK UNIT NUMBER } \\
\text { WBS 645846.02.07.03.11.03 }\end{array}$ \\
\hline \multicolumn{5}{|c|}{$\begin{array}{l}\text { 7. PERFORMING ORGANIZATION NAME(S) AND ADDRESS(ES) } \\
\text { National Aeronautics and Space Administration } \\
\text { John H. Glenn Research Center at Lewis Field } \\
\text { Cleveland, Ohio 44135-3191 }\end{array}$} & $\begin{array}{l}\text { 8. PERFORMING ORGANIZATION } \\
\text { REPORT NUMBER } \\
\text { E-17461 }\end{array}$ \\
\hline \multirow{2}{*}{\multicolumn{5}{|c|}{$\begin{array}{l}\text { 9. SPONSORING/MONITORING AGENCY NAME(S) AND ADDRESS(ES) } \\
\text { National Aeronautics and Space Administration } \\
\text { Washington, DC 20546-0001 }\end{array}$}} & $\begin{array}{l}\text { 10. SPONSORING/MONITOR'S } \\
\text { ACRONYM(S) } \\
\text { NASA }\end{array}$ \\
\hline & & & & & $\begin{array}{l}\text { 11. SPONSORING/MONITORING } \\
\text { REPORT NUMBER } \\
\text { NASA/TM-2010-216902 }\end{array}$ \\
\hline \multicolumn{6}{|c|}{$\begin{array}{l}\text { 12. DISTRIBUTION/AVAILABILITY STATEMENT } \\
\text { Unclassified-Unlimited } \\
\text { Subject Categories: } 35 \text { and } 74 \\
\text { Available electronically at http://gltrs.grc.nasa.gov } \\
\text { This publication is available from the NASA Center for AeroSpace Information, 443-757-5802 }\end{array}$} \\
\hline \multicolumn{6}{|c|}{$\begin{array}{l}\text { 13. SUPPLEMENTARY NOTES } \\
\text { M. Crotty, NASA Glenn Research Center, NASA Undergraduate Student Research Program. }\end{array}$} \\
\hline \multicolumn{6}{|c|}{$\begin{array}{l}\text { 14. ABSTRACT } \\
\text { Two sets of resonances in glass microspheres attached to a standard communication-grade single-mode optical fiber have been observed. It } \\
\text { has been found that the strength of the resonances depends strongly on the polarization of the coupled light. Furthermore, the position of the } \\
\text { resonances in the wavelength domain depends on the polarization of light in the optical fiber with maximum magnitudes shifted by } \\
\text { approximately } 45^{\circ} \text {. }\end{array}$} \\
\hline \multicolumn{6}{|c|}{$\begin{array}{l}\text { 15. SUBJECT TERMS } \\
\text { Optics; Fiber optics; Polarization (Waves); Resonance; Spheres; Optical coupling; Waveguide; Microspheres; Optical resonances }\end{array}$} \\
\hline \multicolumn{3}{|c|}{ 16. SECURITY CLASSIFICATION OF: } & $\begin{array}{l}\text { 17. LIMITATION OF } \\
\text { ABSTRACT }\end{array}$ & $\begin{array}{l}\text { 18. NUMBER } \\
\text { OF }\end{array}$ & $\begin{array}{l}\text { 19a. NAME OF RESPONSIBLE PERSON } \\
\text { STI Help Desk (email:help@sti.nasa.gov) }\end{array}$ \\
\hline $\begin{array}{l}\text { a. REPORT } \\
\text { U }\end{array}$ & $\begin{array}{l}\text { b. ABSTRACT } \\
\text { U }\end{array}$ & $\begin{array}{l}\text { C. THIS } \\
\text { PAGE } \\
\text { U }\end{array}$ & UU & $\begin{array}{l}\text { PAGES } \\
18\end{array}$ & $\begin{array}{l}\text { 19b. TELEPHONE NUMBER (include area code) } \\
443-757-5802\end{array}$ \\
\hline
\end{tabular}



